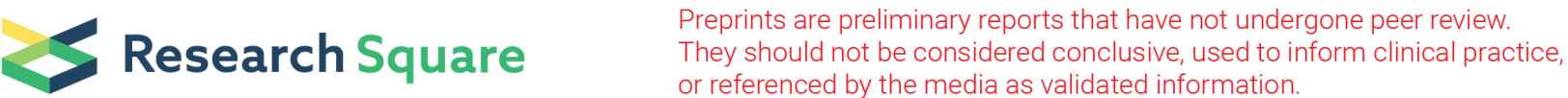

\section{Changes in Hard and Soft Tissue During the First 6 Months After Immediate Implant Placement and Provisionalization of a Single Anterior Maxillary Incisor: A Prospective Cohort Study}

\section{Donghao Wei}

Peking University School and Hospital of Stomatology

\section{Xi Jiang}

Peking University School and Hospital of Stomatology

Ping Di ( $\nabla$ diping@bjmu.edu.cn )

Peking University School and Hospital of Stomatology

Jiehua Tian

Peking University School and Hospital of Stomatology

Ye Lin

Peking University School and Hospital of Stomatology

\section{Research Article}

Keywords: Esthetic zone, immediate placement, soft tissue change, bone, linear analysis

Posted Date: December 16th, 2021

DOI: https://doi.org/10.21203/rs.3.rs-1163093/v1

License: (c) (1) This work is licensed under a Creative Commons Attribution 4.0 International License.

Read Full License 


\section{Abstract}

Background: To evaluate changes in hard and soft tissue during the first 6 months after immediate implant placement and provisionalization (IIPP) of a single maxillary incisor.

Methods: Failed maxillary incisors were replaced with IIP implants in 34 patients. Intraoral scans and cone beam computed tomography (CBCT) were performed before and 6 months after IIPP. Changes in soft tissue thickness, soft tissue contour, and hard tissue contour were measured by a three-dimensional superimposition method. The correlations of hard and soft tissue contour changes were assessed.

Results: A total of 31 patients completed the study. Soft tissue contour tended to collapse after 6 months. Soft tissue was significantly thickened $1-3 \mathrm{~mm}$ below the gingival margin. Correlation analysis showed strong correlations between the hard and soft tissue contour changes at $0-5 \mathrm{~mm}$ apical to the implant platform. The mid-facial recession at 6 months was $-0.46 \pm 0.55 \mathrm{~mm}$.

Conclusions: Soft tissue contour collapsed after tooth extraction, regardless of IIPP. Both soft and hard tissue change affected the soft tissue contour change.

\section{Background}

The esthetic outcome of peri-implant soft tissue is one of the most important considerations following immediate implant placement and provisionalization (IIPP) in the anterior maxillae. $(1,2)$ There is increasing emphasis on achieving an ideal soft tissue contour following IIPP.(3-6) Despite the development of palatal-bias implant placement, flapless surgery,(7) bone grafting in the jumping gap,(8) and immediate provisionalization,(9) varying degrees of facial soft tissue contour collapse have been reported after IIPP treatment. $(3-6,10,11)$ A recent study conducted by our research group revealed a three-dimensional facial soft tissue contour change from the gingival margin to apical region following IIPP, with the greatest soft tissue contour change occurring coronal to the implant platform, approximately $2-3 \mathrm{~mm}$ apical to the gingival margin.(6) Similar clinical results were observed in other studies. $(3,4,12)$

Previous cone beam computed tomography (CBCT) studies confirmed facial bone resorption after immediate implant placement in the extracted socket. Roe et al.(13) reported that the greatest bone contour change occurred at the level of the implant platform, while Morimoto et al.(14) reported a minor change at the implant platform and a major change at the apex. However, from a biological viewpoint, resorption of the facial plate cannot explain the soft tissue contour collapse above the implant platform. The reasons for soft tissue contour changes between the gingival margin and implant platform remain unclear. Recently, studies have found $(15,16)$ that emergence profile design is important for the soft and hard tissue healing. The different emergence profile design and their relation to factors like implant position, implant design, and soft tissue thickness have effect on the facial soft tissue contour. 
Most previous studies reported only facial plate or soft tissue changes, as it is still difficult to accurately and quantitatively analyze soft and hard tissues changes at the same site. The present study was performed to evaluate soft and hard tissue changes during the first 6 months after IIPP based on superimposed CBCT and intraoral scan (IOS) data. The null hypothesis was that soft tissue contour changes are consistent with facial plate changes.

\section{Methods}

\subsection{Patient enrollment}

This prospective cohort study was conducted between January 2018 and June 2020 at Peking University School and Hospital of Stomatology, Department of Implantology. The study was conducted in accordance with the 1975 Declaration of Helsinki, as revised in 2000. The study protocol followed the STROBE statements and was approved by the local ethics committee (Institutional Review Board of Peking University School and Hospital of Stomatology; Approval Numbers: PKUSSIRB-201839133). Subjects provided written informed consent after a comprehensive consultation. Consecutive patients with a single failed maxillary incisor were enrolled in the study. The inclusion and exclusion criteria were as follows:

Inclusion criteria:

- age $\geq 20$ years

- Single failing maxillary incisor (12-22) with the presence of adjacent teeth and a healthy periodontal condition

- Intact facial bone plate when the tooth was extracted

- Adequate bone height apical to root of the failing tooth $(\geq 5 \mathrm{~mm})$

- Good treatment compliance

Exclusion criteria:

- Uncontrolled or serious systemic diseases

- Pregnancy

- Poor local anatomical conditions (parafunctional habits: bruxism, clenching, heavy smoking, poor oral hygiene)

- Implant insertion torque $<35 \mathrm{~N} \cdot \mathrm{cm}$ and unsuitable for provisionalization

- Presence of active infection around the failing tooth

- Undergoing orthodontic treatment

\subsection{Surgical and prosthetic procedures}


Stringent surgical and prosthetic protocols were followed. The surgical procedures were performed by two experienced surgeons (Dr. Lin \& Dr. Jiang). All surgical procedures were preceded by prophylactic antibiotic therapy (cefuroxime $0.25 \mathrm{~g}, 1$ hour before surgery) and oral disinfection $(0.2 \%$ chlorhexidine solution for 1 minute). After administration of local infiltration anesthesia with adrenaline $(1.7 \mathrm{ml}$ of Primacaine ${ }^{\mathrm{TM}}$; Produits Dentaires Pierre Rolland, Merignac, France), atraumatic flapless tooth extraction was performed (Figure 1a-1c). The socket was thoroughly debrided and irrigated with sterile saline. The integrity of the buccal bone wall was meticulously checked by intrasocket probing. Osteotomy was performed on the palatal bone wall for implant placement, with a gap of at least $2 \mathrm{~mm}$ between the buccal bone wall and implant platform (Figure 1d). Immediate implant placement (NobelActive ${ }^{\circledR}$; Nobel Biocare, Göteborg, Sweden) was performed according to the individual anatomical conditions (Table 1). The implant shoulder was placed around $4 \mathrm{~mm}$ apical to the gingival margin with insertion torque $\geq 35$ $\mathrm{N} \cdot \mathrm{cm}$. An appropriate healing abutment was applied. The gap between the implant and buccal bone wall was filled with deproteinized bovine bone particles (Bio-Oss ${ }^{\circledR}, 0.25-1 \mathrm{~mm}$; Geistlich Biomaterials, Wolhusen, Switzerland). The space above the implant shoulder was filled with collagenous bone substitute (Bio-Oss ${ }^{\circledR}$ Collagen; Geistlich Biomaterials) (Figure 1e). Patients were given postsurgical antibiotic therapy, and an analgesic as needed.

Screw-retained provisional restorations were fabricated in the dental laboratory by one experienced technician, and installed approximately 3 hours later (Figure 1f). All patients subsequently received oral hygiene instructions. The definitive restoration was delivered 6 months later. The prosthetic procedures were performed by one experienced prosthodontist. All immediate and permanent restorations were fabricated by the same technician.

Table 1

Characteristics of patients and implant information at $\mathrm{T}_{0}$

\begin{tabular}{|lll|}
\hline Males/females, $\mathbf{n}$ & $\begin{array}{l}\text { Age in years, } \\
\text { mean } \pm \text { SD (range) }\end{array}$ & $\begin{array}{l}\text { Implant site } \\
\mathrm{I}_{1} / \mathrm{I}_{2}\end{array}$ \\
\hline $14 / 17$ & $34.2 \pm 13.8(20-57)$ & $29 / 2$ \\
\hline $\mathrm{I}_{1}$ : central incisor; $\mathrm{I}_{2}$ : lateral incisor; & \\
\hline
\end{tabular}

\subsection{Digital data acquisition}

\subsubsection{Intraoral scan (IOS)}

An experienced operator used an intraoral scanner (3Shape Trios; software version: 2018-1; 3Shape, Copenhagen, Denmark) to obtain a digital impression before tooth extraction ( $T_{0}$ ) (Figure 2a) and after 6 months prior to delivery of the definitive restoration $\left(T_{1}\right)$ (Figure $2 b$ ), following the same scanning strategy. The scan region was from the first premolar to the first premolar (Fig. 2a, 2b, 2g, 2h). All IOS data were exported and saved as standard tessellation language (STL) files. 


\subsubsection{CBCT}

CBCT images (Planmeca ProMax 3D; Planmeca Oy, Helsinki, Finland) of the hard tissue were obtained before tooth extraction (Figure 2a). The parameters were as follows: field of view (FOV), $13 \times 10 \mathrm{~cm}$; acceleration voltage, $90 \mathrm{kV}$; beam currency, $8.0 \mathrm{~mA}$; and voxel size, $0.2 \mathrm{~mm}$. After 6 months of healing, CBCT was performed before delivery of the definitive restoration $\left(T_{1}\right)$ (Figure $2 b$ ). All CBCT data were exported and saved as Digital Imaging and Communications in Medicine (DICOM) files.

(a) $\mathrm{T}_{0}$ IOS, $\mathrm{T}_{1}$ IOS, and $\mathrm{T}_{0}$ CBCT were imported into 3D image analysis software.

(b) $T_{0}$ IOS, $T_{1}$ IOS, and $T_{1}$ CBCT were imported into 3D image analysis software.

(c) Superimposition of IOS and CBCT data based on the adjacent teeth via multi-point registration.

(d) Both $T_{0}$ and $T_{1}$ IOS data were superimposed with $T_{0}$ CBCT.

(e) Both $T_{0}$ and $T_{1}$ IOS data were superimposed with $T_{1}$ CBCT.

$(f-i)$ The same cross-sectional plane passing through the $T_{1}$ gingival margin and the long axis of the implant was made in two superimposed digital models.

(j) Superimposition of the two images in the 2D image analysis software. Soft and hard tissue contour at $T_{1}$ are on the image with the yellow frame; Soft and hard tissue contour at $T_{0}$ are on the image with the blue frame. The transparency of the image with the yellow frame was set to $50 \%$ to show the superimposition results. The restoration and soft tissue outline of the two images overlapped completely.

Table 2

Soft tissue thickness changes and soft tissue contour changes from the $T_{1}$ gingival margin to the implant platform

\begin{tabular}{|lll|}
\hline $\begin{array}{l}\text { Apical to } \mathrm{T}_{1} \text { gingival margin, } \\
\mathrm{mm}\end{array}$ & $\begin{array}{l}\text { Soft tissue thickness changes, } \\
\text { mean } \pm \mathrm{SD}(\boldsymbol{p} \text {-value) }\end{array}$ & $\begin{array}{l}\text { Soft tissue contour changes, } \\
\text { mean } \pm \mathrm{SD}\end{array}$ \\
\hline 1 & $0.31 \pm 0.58(0.003)^{\star}$ & $-1.03 \pm 0.45$ \\
\hline 2 & $0.46 \pm 0.77(0.001) *$ & $-0.94 \pm 0.51$ \\
\hline 3 & $0.34 \pm 0.89(0.034)^{*}$ & $-0.95 \pm 0.47$ \\
\hline 4 & $0.12 \pm 0.83(0.435)$ & $-0.93 \pm 0.50$ \\
\hline 5 & $0.04 \pm 0.66(0.772)$ & $-0.95 \pm 0.56$ \\
\hline *Statistically significant. & & \\
\hline
\end{tabular}

\subsection{Superimposition of CBCT and IOS data}

The STL and DICOM data were exported into 3D image analysis software (NobelClinician; Nobel Biocare). For each patient, the following method was used to superimpose the soft and hard tissue images. 
First, $T_{0}$ and $T_{1} S T L$ data were superimposed with the $T_{1}$ CBCT data via multi-point registration, based on the anatomical landmarks on adjacent teeth (Figures 2c-e). After superimposition, a cross-sectional plane passing through the $T_{1}$ gingival margin and long axis of the implant was set as the measurement plane (Figure $2 \mathrm{~g}$ ). Similarly, STL data at $\mathrm{T}_{0}$ and $\mathrm{T}_{1}$ were superimposed with the $\mathrm{T}_{0}$ CBCT data, and the same measurement plane was determined by complete overlap of the STL data (Figure 2f). A virtual implant was inserted into the superimposed implant image to determine the long axis of the implant.

Second, two screenshots of the measurement plane $\left(T_{0}\right.$ and $\left.T_{1}\right)$ were saved as image files in .jpg format (Figure 2h, 2i). Subsequently, the two screenshots were imported into 2D image analysis software (Digimizer; MedCalc Software Ltd., Mariakerke, Belgium) for further assessment (Figure 2j). In the linear measurement software, the long axis of the implant (Line a) was set as a vertical line and the implant platform (Line $b$ ) was set as a horizontal line. The gingival margin was identified as the coronal-most point of the facial soft tissue contour along Line $a$. The image scale was determined by the implant length. Gingival margins at $T_{0}$ and $T_{1}$ were identified on the images for measurement (Figure 3 ).

\subsection{Measurement of soft tissue changes coronal to the implant platform}

The depth of implant placement was measured as the vertical distance between the implant platform and $T_{1}$ gingival margin. The initial height of the facial plate was assessed by measuring the vertical distance between the initial facial plate crest and gingival margin at $\mathrm{T}_{0}$. Vertical bone change was assessed by measuring the vertical distance between the initial facial plate crest and bone crest at $\mathrm{T}_{2}$ (a negative value represented vertical bone loss after 6 months).

From the $T_{1}$ gingival margin to the implant platform, lines parallel to Line a were placed every $1 \mathrm{~mm}$ and the following parameters were measured at each level (Figure 3). At each measurement level, the following parameters were measured:

- Soft tissue thickness changes: the soft tissue thickness was measured on the line extending from the outline of the facial soft tissue to the outline of the facial bone (or to the outline of the restoration). Changes in soft tissue thickness from $T_{0}$ to $T_{1}$ were calculated (positive values indicate thickening of the soft tissue at $\mathrm{T}_{1}$ ).

- Soft tissue contour changes: the soft tissue contour changes were measured on the line extending from the outline of the facial soft tissue at $T_{0}$ to the outline of the facial soft tissue at $T_{1}$, which is represented by line $A B$ in Figure 3 (negative values indicate that the soft tissue had collapsed at $\mathrm{T}_{1}$ ).

\subsection{Measurement of soft and hard tissue changes apical to the implant platform}

Lines parallel to line $b$ were placed $0,1,2,3,4$, and $5 \mathrm{~mm}$ apical to the implant platform, and the following parameters were measured at each level (Figure 3): 
- Soft tissue thickness changes

- Soft tissue contour changes

- Initial thickness of the facial plate

- Thickness of the facial bone at $T_{1}$

- Hard tissue contour changes: the hard tissue contour changes were measured on the line extending from the outline of the facial plate to the outline of the newly formed bone tissue (negative values indicate resorption of the facial plate at $\mathrm{T}_{1}$ ).

\subsection{Mid-facial recession and gingival symmetry}

Mid-facial recession was assessed by measuring the vertical distance between the $T_{0}$ and $T_{1}$ gingival margins (negative values indicated the occurrence of mid-facial recession). Gingival symmetry between the implant site and contralateral tooth at $T_{0}$ and $T_{1}$ was measured on digital models using reverse engineering software (Geomagic Control X; Geomagic, Morrisville, NC, USA). Negative values indicated that the gingival margin was apical to the gingival margin of the contralateral tooth.

\subsection{Analysis of the reproducibility of the measurement method}

The reproducibility of the measurement method described here was evaluated in preparation for this study. One independent blinded examiner (IW) performed the repeated measurements three times every other week in five randomly chosen participants. The remaining measurements were started only when the intraexaminer Cohen kappa values were $>0.8$.

\subsection{Statistical analysis}

According to our preliminary study on the soft and hard tissue contour changes following IIPP, the correlation coefficient between the hard and soft tissue contour changes was 0.34 . Under conditions of a $=.05, \beta=.10$, the sample size was determined to be 30 patients. Considering an approximate $10 \%$ dropout rate, 34 participants were needed.

All statistical analyses were performed with IBM SPSS Statistics for Windows (version 22.0; IBM Corp., Armonk, NY, USA) and the level of significance was set at $a=0.05$. Descriptive statistics were generated and the Kolmogorov-Smirnov test $(a=0.05)$ was performed for all parameters. All data were normally distributed. The soft tissue thickness change at each level was compared with that at $T_{0}$ using the paired $t$ test. The associations between the hard and soft tissue contour changes were analyzed by Pearson correlation. The magnitude of the correlations was given by the absolute value of the correlation coefficient (|CC|):

- $0.8 \leq|\mathrm{CC}| \leq 1.0$ extremely strong correlation

- $0.6 \leq|\mathrm{CC}|<0.8$ strong correlation

- $0.4 \leq|\mathrm{CC}|<0.6$ moderate correlation 
- $0.2 \leq|\mathrm{CC}|<0.4$ weak correlation

- $0.0 \leq|\mathrm{CC}|<0.2$ very weak or no correlation

\section{Results}

\subsection{Patients}

The data for 31 patients who completed the 6-month follow-up were included in the analysis. Three patients were excluded because they received orthodontic treatment (two patients) or were unable to return at 6 months (one patient). The overall implant survival rate was 100\%. Loosening of the screws of the provisional restoration occurred in eight patients and was easily resolved by repeated tightening without further consequences. No other complications occurred.

\subsection{Outcomes of measured variables}

\subsubsection{Soft tissue changes coronal to the implant platform}

The implant depth was $5.1 \pm 1.0 \mathrm{~mm}$. The initial height of the facial plate was $4.4 \pm 0.95 \mathrm{~mm}$. The vertical bone gain from $T_{0}$ to $T_{1}$ was $0.8 \pm 1.2 \mathrm{~mm}$. The soft tissue thickness and contour changes coronal to the implant platform are listed in Table 2 and shown in Figure 4. At $T_{1}$, soft tissue was significantly thickened 1-3 $\mathrm{mm}$ apical to the $T_{1}$ gingival margin, while at 4 and $5 \mathrm{~mm}$, the soft tissue thickening was not significant.

\subsubsection{Soft and hard tissue changes apical to the implant platform}

The soft tissue thickness and contour changes apical to the implant platform are listed in Table 3 and shown in Figure 4. At $T_{1}$, the soft tissue thickening was not significant $0-5 \mathrm{~mm}$ apical to the implant platform.

The initial thickness of the facial plate, the thickness of the facial bone at $T_{1}$, and the hard tissue contour changes are listed in Table 4 and shown in Figure 4. Strong positive correlations were found between the hard and soft tissue contour changes at $0-5 \mathrm{~mm}$. 
Table 3

Soft tissue thickness and contour changes apical to the implant platform

\begin{tabular}{|lll|}
\hline $\begin{array}{l}\text { Apical to the implant platform, } \\
\mathrm{mm}\end{array}$ & $\begin{array}{l}\text { Soft tissue thickness changes, } \\
\text { mean } \pm \text { SD }(\boldsymbol{p} \text {-value })\end{array}$ & $\begin{array}{l}\text { Soft tissue contour changes, } \\
\text { mean } \pm \text { SD }\end{array}$ \\
\hline 0 & $0.02 \pm 0.94(0.907)$ & $-0.87 \pm 0.48$ \\
\hline 1 & $-0.02 \pm 0.55(0.840)$ & $-0.75 \pm 0.37$ \\
\hline 2 & $-0.12 \pm 0.47(0.823)$ & $-0.65 \pm 0.29$ \\
\hline 3 & $-0.09 \pm 0.52(0.397)$ & $-0.58 \pm 0.36$ \\
\hline 4 & $-0.13 \pm 0.34(0.880)$ & $-0.59 \pm 0.35$ \\
\hline 5 & $0.04 \pm 0.55(0.815)$ & $-0.49 \pm 0.55$ \\
\hline *Statistically significant. & & \\
\hline
\end{tabular}

Table 4

Hard tissue contour changes apical to the implant platform

\begin{tabular}{|lllll|}
\hline $\begin{array}{l}\text { Apical to the } \\
\text { implant platform, } \\
\text { mm }\end{array}$ & $\begin{array}{l}\text { Initial thickness of } \\
\text { the facial plate, } \\
\text { mean } \pm \text { SD }\end{array}$ & $\begin{array}{l}\text { Thickness of the } \\
\text { facial bone at } \mathrm{T}_{1}, \\
\text { mean } \pm \text { SD }\end{array}$ & $\begin{array}{l}\text { Hard tissue } \\
\text { contour } \\
\text { changes, } \\
\text { mean } \pm \text { SD }\end{array}$ & $\begin{array}{l}\text { Correlation } \\
\text { coefficient* }\end{array}$ \\
\hline 0 & $0.64 \pm 0.39$ & $0.72 \pm 0.29$ & $-0.88 \pm 0.95$ & 0.81 \\
\hline 1 & $0.72 \pm 0.29$ & $2.59 \pm 0.93$ & $-0.71 \pm 0.56$ & 0.71 \\
\hline 2 & $0.64 \pm 0.29$ & $2.68 \pm 0.97$ & $-0.64 \pm 0.43$ & 0.645 \\
\hline 3 & $0.64 \pm 0.26$ & $2.56 \pm 0.94$ & $-0.55 \pm 0.36$ & 0.696 \\
\hline 4 & $0.64 \pm 0.25$ & $2.24 \pm 0.86$ & $-0.62 \pm 0.34$ & 0.682 \\
\hline 5 & $0.50 \pm 0.21$ & $1.99 \pm 0.90$ & $-0.60 \pm 0.35$ & 0.763 \\
\hline$*$ Correlation coefficient between the hard and soft tissue contour changes. & \\
\hline
\end{tabular}

\subsubsection{Mid-facial recession}

The mid-facial recession at 6 months was $-0.46 \pm 0.55 \mathrm{~mm}$. The gingival symmetry was $0.10 \pm 0.43 \mathrm{~mm}$ at $\mathrm{T}_{0}$ and $-0.04 \pm 0.50 \mathrm{~mm}$ at $\mathrm{T}_{1}$.

\section{Discussion}

Many studies have reported facial soft tissue contour collapse after IIPP. Although facial plate resorption has been well documented, it is difficult to determine the reasons for facial soft tissue contour collapse. Limited data are available regarding how hard and soft tissues changes affect the soft tissue contour. 
The present study focused on the relationship between tissue remodeling and the soft tissue contour following IIPP, via the superimposition of intraoral and CBCT scans. The null hypothesis was partially accepted. Facial plate resorption was the main reason for soft tissue contour collapse apical to the implant platform. However, this could not explain the soft tissue contour changes coronal to the implant platform.

Accurate quantitative analysis of both soft and hard tissue changes has always proven difficult, especially when the goal is to establish the $3 \mathrm{D}$ relations between soft and hard tissue changes. Few commercial analytical software packages can superimpose multiple CBCT and intraoral scans. CBCT and IOS data were analyzed separately in a recent study by Jiang et al.(3) In the present study, we superimposed the CBCT data before and after IIPP with the IOS data, which allowed for superimposition of all CBCT and IOS data for the same patient. Our 2D image superimposition method was used in previous CBCT studies. $(14,17)$ The measurement plane with the most obvious contour changes was selected based on the results of our previous volumetric analysis.(6)

Chappuis et al.(18) documented the bundle bone resorption pattern in the esthetic zone; they identified a risk zone that was more susceptible to facial plate resorption in central areas. The measurement plane in the present study typically shows the facial plate changes in the risk zone. A mean facial plate resorption of $0.6-0.88 \mathrm{~mm}$ was found $0-5 \mathrm{~mm}$ apical to the implant platform, which exceeded the mean horizontal bone changes in previous CBCT studies. $(13,14)$ This may have been because the present study focused on the incisors, which are more sensitive to facial plate resorption.(19) Greater horizontal bone resorption occurred at the implant platform level, consistent with the study of Roe et al.(13) Three cases in our study showed minimal facial plate resorption $(<0.10 \mathrm{~mm})$ apical to the implant platform, which may have been due either to deeper (about $2 \mathrm{~mm}$ depth from the facial bone crest) implant placement (two cases) or a thicker facial plate (one case).

Apical to the implant platform, resorption of the facial plate was closely related to soft tissue contour collapse. We found that the facial plate was almost completely resorbed after 6 months in most patients, while the soft tissue thickness showed little change, indicating that contour collapse was due to facial plate resorption. As expected, new bone formation was seen within the facial plate at 6 months, in line with previous studies. $(13,14)$

For esthetic reasons, bone-level implants are recommended, and a crestal or sub-crestal implant position is advantageous to avoid interference with soft tissue healing. This prolongs the emergence time and results in a change from peritooth to supraimplant soft tissue.(20) To avoid pressure on the facial soft tissue, palatal-bias implant placement and a concave emergence profile of the provisional restoration are recommended.(16) As shown in Figure 5, the shape of the emergence profile of the provisional restoration was quite different from the neck of the original tooth (Figure 5, red shaded region), which created a space between the provisional restoration and soft tissue. Bone substitutes were grafted into the space. However, CBCT at 6 months revealed resorption of most of the bone graft materials $1-3 \mathrm{~mm}$ apical to the gingival margin, and the space was mainly occupied by the thickened soft tissue. Differences in 
osteogenesis inside and outside the facial plate have been reported, but little evidence has been reported regarding the effect of this difference on the appearance of facial soft tissue.

New bone formation was predictable in the inner facial plate, while new bone formation could not be predicted in the space outside the facial plate. A medium-to-high-density area was seen a mean of 0.8 $\mathrm{mm}$ coronal to the initial facial bone crest. However, histologically, we could not determine whether this high-density area was newly formed bone on CBCT. A previous study reported maintenance of a facial vertical bone level up to $0.56 \mathrm{~mm}$ coronal to the implant platform at 1 year after IIPP in some cases.(14) Grafted materials were almost completely resorbed 1-3 mm apical to the gingival margin. This may have been due to the reduced blood supply and poorer stability in this region.

As well as the facial hard tissue, the facial soft tissue changed after IIPP treatment. The soft tissue at 1$3 \mathrm{~mm}$ apical to the gingival margin showed significant thickening, which was rarely reported in previous studies. On 2D cross-section, the shape of the facial soft tissue changed from a slender strip to an inverted triangle. From a biological viewpoint, palatal-bias placement of a small-diameter implant, and the concave provisional restoration, changed the gingival shape and biotype from thin to thick(15). Interestingly, the soft tissue thickening could not fully compensate for the soft tissue collapse in this region.

With resorption of the facial bundle bone, the corresponding facial soft tissue showed no changes. We speculate that the significant thickening of soft tissue near the gingival margin may have been related to the sudden loss of hard tissue support following tooth extraction. Once the tooth had been removed, the soft tissue experienced a sudden loss of hard tissue support. The provisional restoration and granular substitutes could not stabilize the soft tissue in situ. In a recent study, Wang et al.(4) reported a similar finding. where facial soft tissue collapsed at immediately placed implants was independent of immediate provisionalization. Similar to the soft tissue above the facial plate, facial bone resorption was relatively slow, so the soft tissue gradually adapted to the bone tissue remodeling and was almost unchanged.

The socket shield technique has been proposed to maintain the denture-supporting tissue and minimize the negative effects of extraction. Minor contour collapse on the facial side in the faciopalatal direction was reported either during the healing period or over the long term. $(21,22)$ We speculated that the positive effect of bone grafting coronal to the facial plate on soft tissue contour maintenance may be quite limited. Stable support of facial tissue during the early healing period seems to be important for contour maintenance.

Mid-facial recession in our patients was similar to previous studies.(5) At $T_{1}$, the gingival margin of the implant and contralateral tooth showed satisfactory symmetry; the reasons for discrepancies between the two parameters were investigated and discussed in our previous study.(6)

This study had some limitations. First, this was a 6-month observational study to determine general patterns of soft and hard tissue remodeling. Bone alterations occurred continuously, which should be further assessed through long-term observation.

Page $11 / 20$ 


\section{Conclusions}

With consideration of the limitations of this study, soft tissue contour collapsed after tooth extraction, regardless of IIPP. Both soft and hard tissue changes affected the soft tissue contour change.

\section{Abbreviations}

IIPP Immediate implant placement and provisionalization

CBCT Cone beam

IOS Intraoral scan

\section{Declarations}

Ethics approval and consent to participate: All procedures performed in studies involving human participants were in accordance with the ethical standards of the institutional and/or national research committee and with the 1964 Helsinki declaration and its later amendments or comparable ethical standards. Informed consent was obtained from all individual participants included in the study.

Consent for publication: Not applicable

Availability of data and materials: All data generated or analysed during this study are included in this published article [and its supplementary information files].

Competing interests: The authors declare that they have no competing interests

Funding: the study was unfunded.

Authors' contributions: all authors have read and approved the manuscript

Donghao Wei: Study design; data collection and analysis; drafting article.

Xi Jiang: Study design; data collection; clinical intervention

Ping Di: Concept; critical revision of article.

Jiehua Tian: Data collection and analysis; statistics

Ye Lin: Critical revision of article; clinical intervention

Acknowledgements: The authors would like to thank Hongyan Cui, the master dental technician from Department of Oral Implantology at Peking University School and Hospital of Stomatology in Beijing for her support in techniques and materials. The authors thank Mr. Xingmao Yin for his voluntary technical support in software. 
Authors' information (optional):

Donghao Wei, DMD, Department of Oral Implantology, Peking University School and Hospital of Stomatology, Beijing, PR China;

Xi Jiang, DMD; Associated Doctor in Chief, Department of Oral Implantology, Peking University School and Hospital of Stomatology, Beijing, PR China

Ping Di, DMD; Professor and Chairman, Department of Oral Implantology, Peking University School and Hospital of Stomatology, Beijing, PR China;

Jiehua Tian, DMD, Department of Oral Implantology, Peking University School and Hospital of Stomatology, Beijing, PR China;

Ye Lin, DMD; Professor, Department of Oral Implantology, Peking University School and Hospital of Stomatology, Beijing, PR China;

\section{Corresponding Author}

Dr.Ping Di, DMD, Professor and Chairman, Department of Oral Implantology, Peking University, School and Hospital of Stomatology, Beijing 100081, PR China; e-mail: diping@bjmu.edu.cn

\section{References}

1. Raes S, Eghbali A, Chappuis V, Raes F, De Bruyn H, Cosyn J. A long-term prospective cohort study on immediately restored single tooth implants inserted in extraction sockets and healed ridges: CBCT analyses, soft tissue alterations, aesthetic ratings, and patient-reported outcomes. Clin Implant Dent Relat Res. 2018;20(4):522-30.

2. Cosyn J, Eghbali A, Hermans A, Vervaeke S, De Bruyn H, Cleymaet R. A 5-year prospective study on single immediate implants in the aesthetic zone. J Clin Periodontol. 2016;43(8):702-9.

3. Jiang X, Di P, Ren SX, Zhang Y, Lin Y. Hard and soft tissue alterations during the healing stage of immediate implant placement and provisionalization with or without connective tissue graft: A randomized clinical trial. J Clin Periodontol. 2020;47(8):1006-15.

4. Wang IC, Chan HL, Kinney J, Wang HL. Volumetric facial contour changes of immediately placed implants with and without immediate provisionalization. J Periodontol. 2020;91(7):906-16.

5. van Nimwegen WG, Raghoebar GM, Zuiderveld EG, Jung RE, Meijer HJA, Muhlemann S. Immediate placement and provisionalization of implants in the aesthetic zone with or without a connective tissue graft: A 1-year randomized controlled trial and volumetric study. Clin Oral Implants Res. 2018;29(7):671-8.

6. Tian J, Wei D, Zhao Y, Di P, Jiang X, Lin Y. Labial soft tissue contour dynamics following immediate implants and immediate provisionalization of single maxillary incisors: A 1-year prospective study. Clin Implant Dent Relat Res. 2019;21(3):492-502. 
7. Stoupel J, Lee CT, Glick J, Sanz-Miralles E, Chiuzan C, Papapanou PN. Immediate implant placement and provisionalization in the aesthetic zone using a flapless or a flap-involving approach: a randomized controlled trial. J Clin Periodontol. 2016;43(12):1171-9.

8. Chu SJ, Salama MA, Garber DA, Salama H, Sarnachiaro GO, Sarnachiaro E, et al. Flapless Postextraction Socket Implant Placement, Part 2: The Effects of Bone Grafting and Provisional Restoration on Peri-implant Soft Tissue Height and Thickness- A Retrospective Study. Int J Periodontics Restorative Dent. 2015;35(6):803-9.

9. Cabello G, Rioboo M, Fabrega JG. Immediate placement and restoration of implants in the aesthetic zone with a trimodal approach: soft tissue alterations and its relation to gingival biotype. Clin Oral Implan Res. 2013;24(10):1094-100.

10. Cosyn J, Eghbali A, De Bruyn H, Collys K, Cleymaet R, De Rouck T. Immediate single-tooth implants in the anterior maxilla: 3-year results of a case series on hard and soft tissue response and aesthetics. J Clin Periodontol. 2011;38(8):746-53.

11. Raes F, Cosyn J, Crommelinck E, Coessens P, De Bruyn H. Immediate and conventional single implant treatment in the anterior maxilla: 1-year results of a case series on hard and soft tissue response and aesthetics. J Clin Periodontol. 2011;38(4):385-94.

12. Arora H, Ivanovski S. Immediate and early implant placement in single-tooth gaps in the anterior maxilla: A prospective study on ridge dimensional, clinical, and aesthetic changes. Clin Oral Implants Res. 2018;29(11):1143-54.

13. Roe P, Kan JY, Rungcharassaeng K, Caruso JM, Zimmerman G, Mesquida J. Horizontal and vertical dimensional changes of peri-implant facial bone following immediate placement and provisionalization of maxillary anterior single implants: a 1-year cone beam computed tomography study. Int J Oral Maxillofac Implants. 2012;27(2):393-400.

14. Morimoto T, Tsukiyama Y, Morimoto K, Koyano K. Facial bone alterations on maxillary anterior single implants for immediate placement and provisionalization following tooth extraction: a superimposed cone beam computed tomography study. Clin Oral Implants Res. 2015;26(12):1383-9.

15. Gomez-Meda R, Esquivel J, Blatz MB. The esthetic biological contour concept for implant restoration emergence profile design. J Esthet Restor Dent. 2021;33(1):173-84.

16. Gonzalez-Martin O, Lee E, Weisgold A, Veltri M, Su H. Contour Management of Implant Restorations for Optimal Emergence Profiles: Guidelines for Immediate and Delayed Provisional Restorations. Int J Periodontics Restorative Dent. 2020;40(1):61-70.

17. Jiang $X$, Zhang Y, Di P, Lin Y. Hard tissue volume stability of guided bone regeneration during the healing stage in the anterior maxilla: A clinical and radiographic study. Clin Implant Dent Relat Res. 2018;20(1):68-75.

18. Chappuis V, Engel O, Reyes M, Shahim K, Nolte LP, Buser D. Ridge alterations post-extraction in the esthetic zone: a 3D analysis with CBCT. J Dent Res. 2013;92(12 Suppl):195S-201S.

19. Ferrus J, Cecchinato D, Pjetursson EB, Lang NP, Sanz M, Lindhe J. Factors influencing ridge alterations following immediate implant placement into extraction sockets. Clin Oral Implants Res. 
2010;21(1):22-9.

20. Joda T, Ferrari M, Gallucci GO, Wittneben JG, Bragger U. Digital technology in fixed implant prosthodontics. Periodontol 2000. 2017;73(1):178-92.

21. Hinze M, Janousch R, Goldhahn S, Schlee M. Volumetric alterations around single-tooth implants using the socket-shield technique: preliminary results of a prospective case series. Int $\mathrm{J}$ Esthet Dent. 2018;13(2):146-70.

22. Baumer D, Zuhr O, Rebele S, Hurzeler M. Socket Shield Technique for immediate implant placement clinical, radiographic and volumetric data after 5 years. Clin Oral Implants Res. 2017;28(11):1450-8.

\section{Figures}



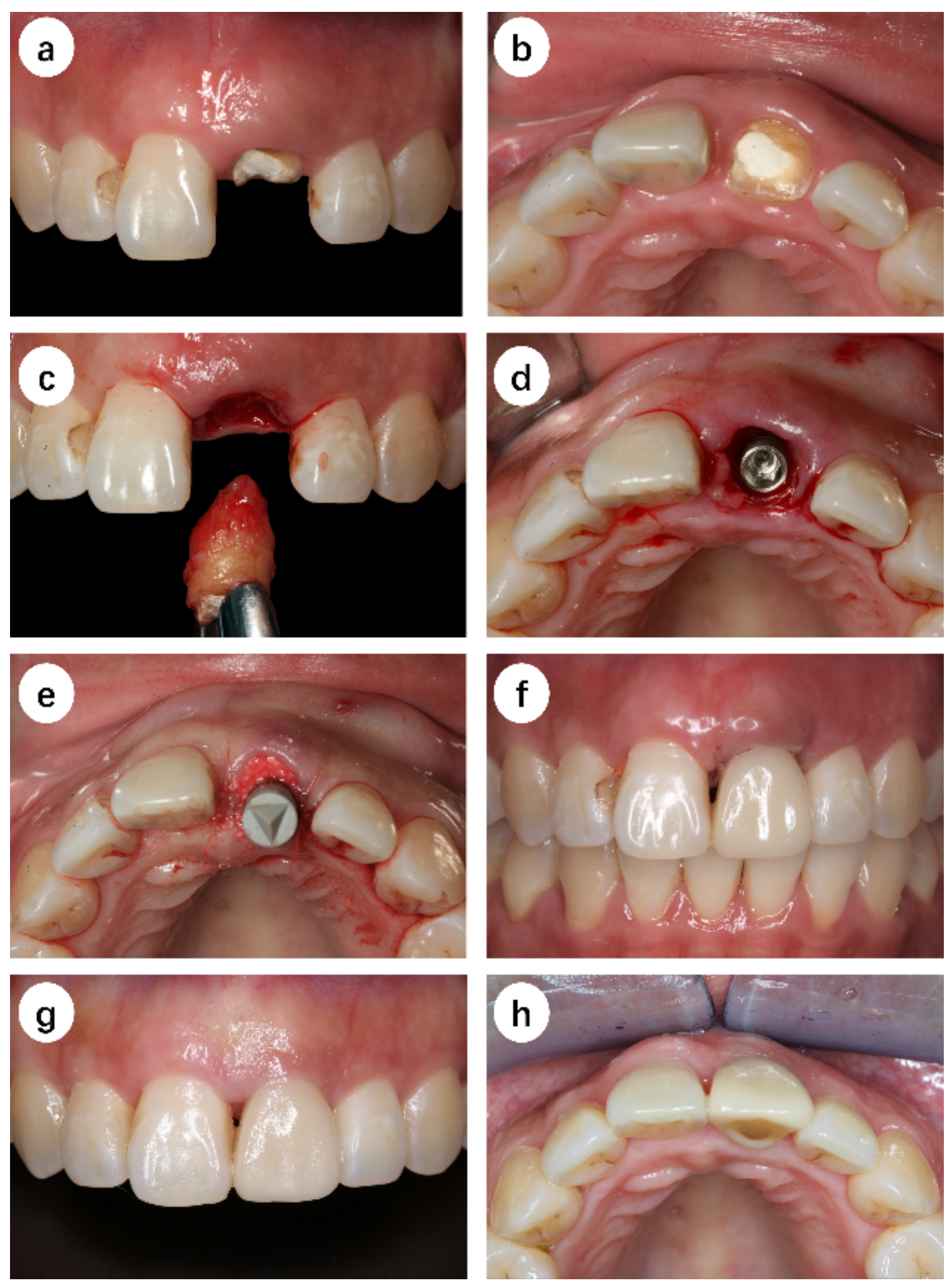

\section{Figure 1}

(a) Facial view at $T_{0}$. (b) Occlusal view at $T_{0}$. (c) Atraumatic extraction of the unsalvageable tooth. (d) Implant placement at the socket. (e) Bone graft in the gap. (f) Immediate provisionalization. (g) Facial view at $T_{1}$. (h) Occlusal view at $T_{1}$. 


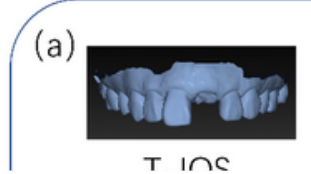

$T$ inc

\section{(1)

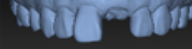 \\ $T$ inc}

Step 1: IOS and CBCT data

\section{Figure 2}

Superimposition method of CBCT and STL data. 


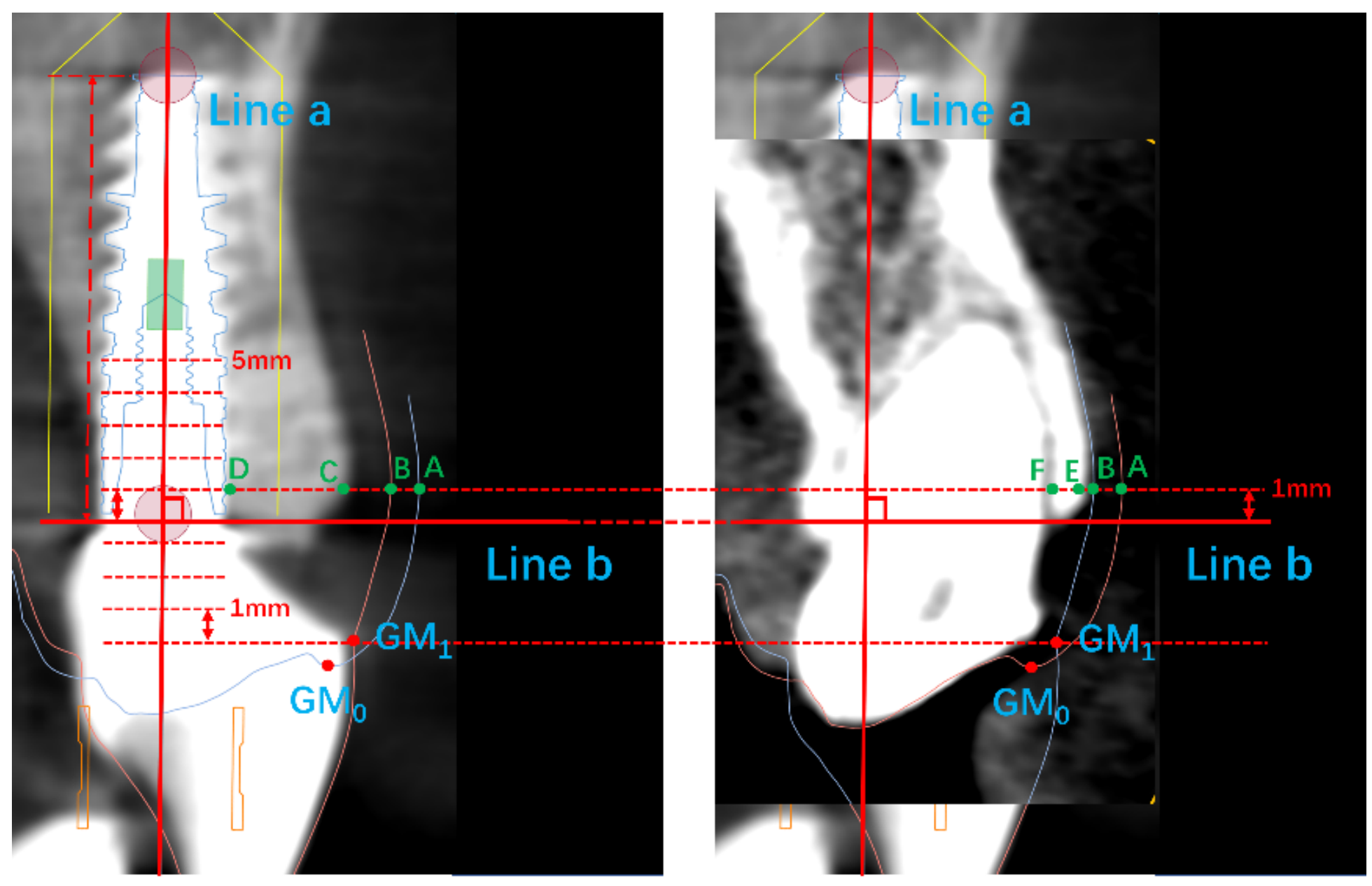

Figure 3

Identification of the anatomical and implant landmarks. The long axis of the implant (line a), implant platform level (line $b$ ), and gingival margins at $T_{0}$ and $T_{1}$ were determined on the images $\left(G_{0}\right.$ and $G M_{1}$, respectively). Line $A B$ : soft tissue contour change; line $A E$ : soft tissue thickness at $T_{0}$; line $E F$ : facial plate thickness; line $B C$. soft tissue thickness at $\mathrm{T}_{1}$; line $C D$. bone tissue thickness at $\mathrm{T}_{1}$. 


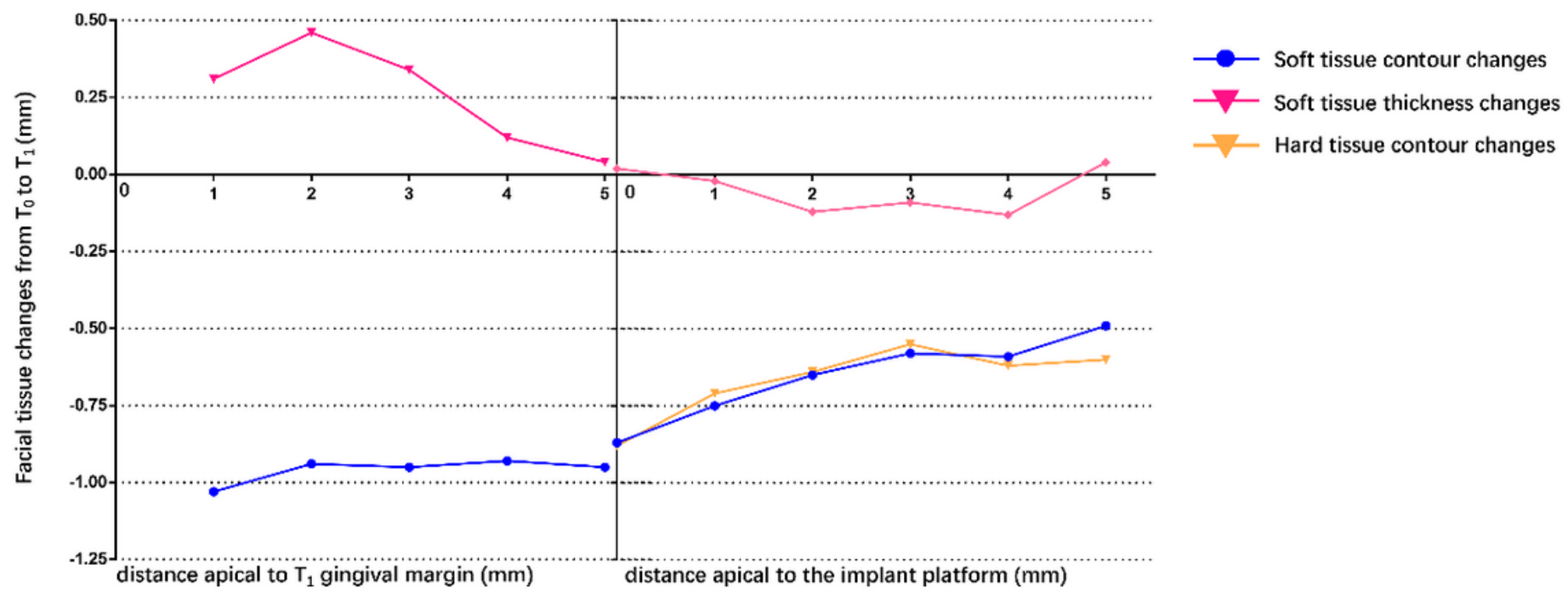

\section{Figure 4}

Soft and hard tissue contour changes. The $X$-axis represents the distance apical to the $T_{1}$ gingival margin (left) and the implant platform (right), and the Y-axis shows the values of the parameters ( $\mathrm{mm}$ ). 
Soft tissue and facial plate contour at $\mathrm{T}_{0}$

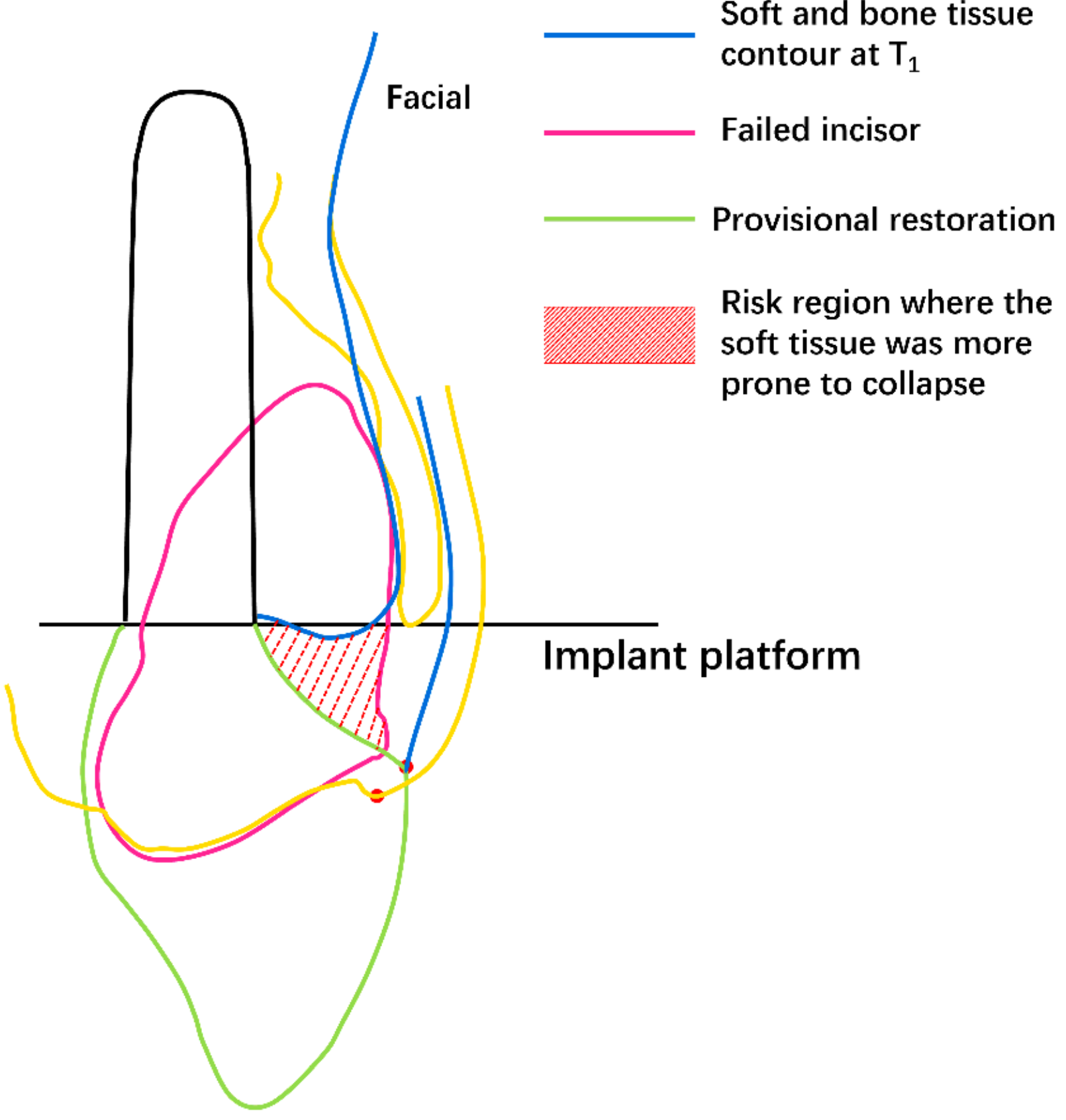

Figure 5

Schematic diagram of soft and hard tissue changes. The tooth contour and soft tissue and facial plate contour at $\mathrm{T}_{0}$ are shown by pink and yellow lines, respectively. The provisional restoration contour, and soft and bone tissue contour at $\mathrm{T}_{1}$ are shown by green and blue lines, respectively. The soft tissue contour was more prone to collapse in the risk region (red-shaded region). 